\title{
Geriatrics Fact Sheet in Korea 2018 From National Statistics
}

\author{
II-Young Jang, Hea Yon Lee, Eunju Lee; The 50th Anniversary Committee of Korean Geriatrics Society \\ Division of Geriatrics, Department of Internal Medicine, Asan Medical Center, University of Ulsan College of Medicine, Seoul, Korea
}

Corresponding Author:

Eunju Lee, MD, PhD

https://orcid.org/0000-0003-4612-0625

Division of Geriatrics, Department of Internal Medicine, Asan Medical Center, University of Ulsan College of Medicine, 88 Olympic-ro 43-gil, Songpa-gu, Seoul 05505, Korea

E-mail: eunjulee@amc.seoul.kr

Received: March 22, 2019

Revised: May 8, 2019

Accepted: May 9, 2019
South Korea is the fastest aging country in the world, having become an aged society in 2017, with over $14 \%$ of its population aged 65 years or older. This Korean Geriatrics Fact Sheet 2018 aimed to overview and clarify the current geriatric burden and its trends in South Korea. Using nationwide surveys and public reports from government or related organizations, especially the 2017 Survey of the Living Conditions and Welfare Needs of Korean Older Persons from the Korea Institute for Health and Social Affairs, our committee has summarized the profile, socioeconomic status, health-related lifestyles, geriatric syndromes with major comorbidities, and use of healthcare services in the aging population. We hope that this review will publicize the social burden and seriousness of the aging problem in Korea. (Ann Geriatr Med Res 2019;23:50-53)

Key Words: Aged, Frail elderly, Health services for the aged, Residence characteristics, Cost of illness

\section{INTRODUCTION}

South Korea is the world's fastest-aging country among the aging global population. After the Korean war in 1950 and its subsequent "baby boom", more than $14 \%$ of the population of Korea was aged 65 years or older in 2017, a population close to 7.12 million. ${ }^{1)}$ It took 17 years for South Korea to progress from an aging to an aged society, compared to the 24 years required for Japan to make the same transition. Moreover, the low birth rate in 2018, as low as 0.98 , has accelerated the pace of aging and is rapidly increasing the social burden of the geriatric population. $^{2)}$

In order to understand the seriousness of Korean aging and its socioeconomic burden, the 50th Anniversary Committee of the Korean Geriatrics Society launched the Fact Sheet Project in 2018. Although community-based research has been published in Korea, ${ }^{3-6)}$ we have prioritized the report from government-led nationwide surveys in consideration of population selection, assessment tools, and standardized methodologies. In particular, the present review mainly quoted the results of the Survey of the Living Conditions and Welfare Needs of the Korean Older Persons from the Korea Institute for Health and Social Affairs. ${ }^{7)}$ Briefly, every three years since 2008, this survey has investigated the health status and medical welfare needs of older adults. From June to August 2017, face-toface interviews of 10,299 older individuals aged 65 years and above who were extracted by stratified two-stage cluster sampling were conducted nationwide. ${ }^{7)}$ Otherwise, official reports from National Statistical Database, Ministry of the Interior and Safety, Ministry of Health and Welfare, National Health Insurance Service, Health Insurance Review and Assessment Service, Korea Centers for Disease Control and Prevention, National Dementia Center and Organization for Economic Cooperation and Development Health were also used in this review. ${ }^{8-12)}$

\section{PROFILE OF AGING IN KOREA}

In August 2017, the population aged 65 years or more was projected to comprise $13.8 \%$ of the total population in Korea (Supplementary materials 1 and 2, pages 5). According to the Korean Statistical Information Service, the gap between life expectancy and health adjusted life expectancy was about 17.5 years (Supplementary materials 1 and 2, pages 6 and 7).

\section{SOCIOECONOMIC STATUS OF KOREAN OLDER ADULTS}

Due to the Korean War in 1950, the Korean education system during that period had a weak foundation. More than half of the older population (58.4\%) received less than six years of elementary school education and 24.3\% did not receive any formal education (Supplementary materials 1 and 2, page 9). The education level was relatively low in older adults living alone. The proportion of individuals living alone has increased rapidly from $16.0 \%$ in 2000 to 
23.6\% in 2018 (Supplementary materials 1 and 2, page 10).

The hardships in life encountered by older Koreans include health-related problems (40.7\% of individuals) and economic difficulties (40.1\% of individuals) (Supplementary materials 1 and 2, page 11). The old-age dependency ratio, which measures the number of older adults as a ratio of those of working age, was 17.5 in 2015, is expected to increase to 21.8 in 2020, and will show a steep, steady increase by 2060 .

\section{HEALTH-RELATED LIFESTYLES IN OLDER ADULTS}

The Nutritional Screening Initiative identified that 58.7\% of older adults aged 65 years or older either need nutritional attention or improvement. With increasing age, the percentages of these two groups have also increased consistently (Supplementary materials 1 and 2, page 13). Korean older adults spent an average of 8.2 hours per day sitting or lying down (Supplementary materials 1 and 2, page 14) and 51.9\% had insufficient exercise (Supplementary materials 1 and 2, page 15), with lower exercise rates in rural compared to urban populations. The most common exercise methods were walking (35.4\%) and other aerobic exercise (34.4\%). Only $15.2 \%$ of individuals practiced resistance exercise regularly, including only $8.4 \%$ of females (Supplementary materials 1 and 2, page 14). Overall, 21.5\% of older adults in Korea had insufficient leg strength. When asked about their health status, 39.7\% of the older people thought their health was bad and 44.2\% did not feel satisfied with their health (Supplementary materials 1 and 2, page 16).

\section{GERIATRIC SYNDROMES AND COMMON COMORBIDITIES}

\section{Functional Status and Disability}

Functional status, also known as the sixth vital sign, ${ }^{13)}$ represents the clinical outcomes of comorbidities, frailty, sarcopenia, or cognitive decline. Functional status is assessed according to activities of daily living and instrumental activity. In summary, 8.7\% of older individuals in Korea had limitations in activities of daily living and $16.6 \%$ had limitations in instrumental activities of daily living (Supplementary materials 1 and 2, page 18). Difficulties in daily living were present in $25.3 \%$ of the total older population and $43.9 \%$ of those aged $80-84$ years had a disability. Among older adults aged 65 years and above, $46.2 \%$ reported having difficulty in chewing, 33.9\% had impaired visual acuity, and 17.8\% had difficulty in hearing (Supplementary materials 1 and 2, page 19). A total of 12,619 patients were treated for swallowing difficulties and 52.9\% were over 70 years of age in 2016 (Supplementary materials 1 and 2, page 19).

\section{Common Medical Comorbidities}

The Survey of the Living Conditions and Welfare Needs of Korean Older Persons in 2017 defined chronic diseases as physician-diagnosed illnesses lasting for more than three months. ${ }^{1)}$ By this definition, 89.5\% of the older population had one or more chronic diseases, 73\% had two or more, and $51.0 \%$ had three or more chronic diseases in 2017, compared to $30.7 \%$ of the older population with three or more comorbidities in 2008 (Supplementary materials 1 and 2, page 20).

The most common chronic diseases among older people were hypertension (59.0\%), osteoarthritis (33.1\%), hyperlipidemia (29.5\%), back pain (24.1\%), and diabetes (23.2\%) (Supplementary materials 1 and 2, page 21). In 2016, there were 4.40 million hypertensive patients, $46 \%$ of whom were older patients (Supplementary materials 1 and 2, page 24). There were also 2.7 million individuals with diabetes and, among those aged 70 years and above, the prevalence of diabetes was higher in females than in males. In terms of obesity defined as a body mass index greater than $25 \mathrm{~kg} / \mathrm{m}^{2}$, the prevalence in males decreased with age, at 30.3\% among those aged 70 years or older. However, the prevalence in females increased with age, at $42.2 \%$ in the same age group (Supplementary materials 1 and 2, page 27).

Regarding common geriatric syndromes, 21.1\% had depressive symptoms and 13.2\% had attempted suicide (Supplementary materials 1 and 2, page 21). The reasons for suicidal ideation were economic difficulties $(27.7 \%$ of individuals) and health problems (27.6\% of individuals). About $15.9 \%$ of older adults had experienced a fall in the previous year, with an average of 2.1 fall events per year (Supplementary materials 1 and 2, page 26). The reason for falls included slippery floors (26.4\%) and weak legs $(20.1 \%)$. The prevalence of osteoporosis and dementia was $13.0 \%$ and 10.2\%, respectively (Supplementary materials 1 and 2, pages 22 and 26). Although there are more than 720,000 dementia patients in Korea, fewer than 46\% received screening tests for dementia.

\section{Sarcopenia and Frailty}

The prevalence of sarcopenia among older Korean adults from population-based community cohorts studies varied from 5.2\%-16.5\% based on height-adjusted appendicular skeletal muscle mass measurements (Table 1). ${ }^{14-17)}$ The prevalence of frailty among older Korean adults, as defined by the Cardiovascular Health Study frailty phenotype, ranged from $8.3 \%-17 \%$ (Table 2). ${ }^{18-20)}$

\section{USE OF HEALTHCARE SERVICES}

In 2017, the annual national medical expenses for older adults totaled 27.6 trillion won, accounting for 39.9\% of the total medical expenses (Supplementary materials 1 and 2, page 29). Among older adults, 77.4\% visited medi- 
Table 1. Prevalence of sarcopenia among older adults from population-based community cohorts in Korea

\begin{tabular}{|c|c|c|c|c|c|}
\hline First author & Data sources & Number & Prevalence of sarcopenia & Criteria & Publication year \\
\hline Lim et al. ${ }^{14)}$ & KLoSHA & 565 & $\begin{array}{l}\text { All: } 5.2 \% \\
\text { Males: } 6.3 \% \\
\text { Females: } 4.1 \%\end{array}$ & $\begin{array}{l}\text { Skeletal muscle mass defined by ASM / } \\
\text { height }^{2}<1 \text { SD of healthy young adults }\end{array}$ & 2010 \\
\hline Kim et al. ${ }^{15)}$ & 2008-2010 KNHANES & 3,284 & $\begin{array}{l}\text { All: } 4.0 \% \\
\text { Males: } 9.3 \% \\
\text { Females: } 0.2 \%\end{array}$ & $\begin{array}{l}\text { Skeletal muscle defined by ASM / height } \\
<2 \text { SD of healthy young adults }\end{array}$ & 2015 \\
\hline & KLoSHA & 556 & $\begin{array}{l}\text { All: } 8.8 \% \\
\text { Males: } 8.8 \% \\
\text { Females: } 8.8 \%\end{array}$ & EWGSOP-ASM / height ${ }^{2}$ (2010) & \\
\hline Jang et al. ${ }^{16)}$ & ASPRA & 1,343 & $\begin{array}{l}\text { All: } 16.5 \% \\
\text { Males: } 14 \% \\
\text { Females: } 18.5 \%\end{array}$ & AWGS (2014) & 2018 \\
\hline Kim et al. ${ }^{17)}$ & KFACS & 1,222 & $\begin{array}{l}\text { All: } 10.2 \% \\
\text { Males: } 11.4 \% \\
\text { Females: } 9.1 \%\end{array}$ & AWGS (2014) & 2018 \\
\hline
\end{tabular}

KLoSHA, Korean Longitudinal Study on Health and Aging; ASM, appendicular skeletal muscle mass; SD, standard deviation; KNHANES, Korean National Health and Nutrition Examination Survey; EWGSOP, European Working Group on Sarcopenia in Older People; ASPRA, Aging Study of PyeongChang Rural Area; AWGS, Asian Working Group for Sarcopenia; KFACS, Korean Frailty and Aging Cohort Study.

Table 2. Prevalence of frailty among older adults from population-based community cohorts in Korea

\begin{tabular}{|c|c|c|c|c|c|}
\hline \multirow{2}{*}{ First author } & \multirow{2}{*}{ Data sources } & \multirow{2}{*}{ Regions } & \multicolumn{2}{|c|}{ Prevalence of frailty } & \multirow{2}{*}{ Publication year } \\
\hline & & & CHS phenotype & K-FRAIL scale & \\
\hline Park et al. ${ }^{18)}$ & $\begin{array}{l}2008 \text { Survey of the living conditions and } \\
\text { welfare needs of the Korean older persons }\end{array}$ & Urban and rural & $8.3 \%$ & NA & 2008 \\
\hline Jung et al. ${ }^{19)}$ & KLoSHA & Urban & $13.2 \%$ & NA & 2014 \\
\hline Jung et al..$^{5}$ & ASPRA & Rural & $17 \%$ & $27 \%$ & 2016 \\
\hline Kim et al. ${ }^{20)}$ & KFACS & Urban and rural & $11.2 \%$ & $12.4 \%$ & 2018 \\
\hline
\end{tabular}

CHS, Cardiovascular Health Study; K-FRAIL, Korean version of the Fatigue, Resistance, Ambulation, Illnesses, and Loss of weight questionnaire; KLoSHA, Korean Longitudinal Study on Health and Aging; ASPRA, Aging Study of PyeongChang Rural Area; KFACS, Korean Frailty and Aging Cohort Study.

cal facilities more than once a month and 19.9\% visited more than four times a month (Supplementary materials 1 and 2, page 30). Regarding hospitalization, 16.8\% of older adults had been hospitalized within the previous year (Supplementary materials 1 and 2, page 30). An average of 4.1 medications was taken for three months or more, with $38.9 \%$ of older adults regularly taking more than five drugs (Supplementary materials 1 and 2, page 31).

There are more than 250,000 beds in 1,428 long-term care hospitals in Korea. Among nursing facilities, 3,136 nursing homes can accommodate approximately 150,000 people (Supplementary materials 1 and 2, page 32). The rate of health screening in older adults was 82.9\%, 50.1\% of whom responded that they were unable to receive medical treatment due to economic difficulties (Supplementary materials 1 and 2, page 33). Moreover, 91.8\% of the older adults were against life-sustaining treatment (Supplementary materials 1 and 2, page 34).

\section{CONCLUSION}

These national data show an extensive geriatric burden in Korean older adults. This information and index will be of utility to healthcare professionals and policymakers not only to raise awareness but to give priority to the promotion of healthy aging, reinforce geriatric care, and yield aged-friendly public health policies.

\section{CONFLICTS OF INTEREST DISCLOSURES}

The researchers claim no conflicts of interest.

\section{ACKNOWLEDGMENTS}

This project was supported by the 2018 research fund from the Korean Geriatrics Society. We are indebted to the members of 50th Anniversary Project of the Korean Geriatrics Society for their administrative support and efforts in data collection and summarization. 


\section{Members of 50th Anniversary Project of Korean Geriat- rics Society}

Hyun Wook Baik, Dong Ho Lee, Hyung Joon Yoo, Jong Lull Yoon, Hongwoo Nam, Soo Lim, Be Long Cho, Dong Woo Lee, Jae-Young Lim, Nam-Jong Paik, Hyuk Ga, Cheol Min Shin, Eun Jung Park, Ki Young Son, Jong Kyoung Choi

\section{SUPPLEMENTARY MATERIALS}

Supplementary materials 1 and 2 can be found with this article online (Supplementary material 1: http:// pdf.medrang.co.kr/KGS2/2019/023/agmr-23-02-s001. pdf; Supplementary material 2: http://pdf.medrang.co.kr/ KGS2/2019/023/agmr-23-02-s002.pdf).

\section{REFERENCES}

1. Korean Statistical Information Service (KOSIS). Annual report on the cause of death statistics 2018 [Internet]. Daejeon: Statistics Korea [cited 2018 Jul 10]. Available from: http://kosis.kr/search/ search.do?query=\%EC\%82\%AC\%EB\%A7\%9D\%EC\%9B\%90\%EC $\% 9 \mathrm{D} \% \mathrm{~B} 8$.

2. Statistics Korea. Population and housing census 2017 [Internet]. Daejeon: Statistics Korea [cited 2019 Feb 28]. Available from: http://kostat.go.kr/portal/korea/.

3. Han JW, Kim TH, Kwak KP, Kim K, Kim BJ, Kim SG, et al. Overview of the Korean longitudinal study on cognitive aging and dementia. Psychiatry Investig 2018;15:767-74.

4. Lee EY, Kim HC, Rhee Y, Youm Y, Kim KM, Lee JM, et al. The Korean urban rural elderly cohort study: study design and protocol. BMC Geriatr 2014;14:33.

5. Jung HW, Jang IY, Lee YS, Lee CK, Cho EI, Kang WY, et al. Prevalence of frailty and aging-related health conditions in older Koreans in rural communities: a cross-sectional analysis of the aging study of Pyeongchang rural area. J Korean Med Sci 2016;31:34552.

6. Won CW, Lee Y, Choi J, Kim KW, Park Y, Park H, et al. Starting construction of frailty cohort for elderly and intervention study. Ann Geriatr Med Res 2016;20:114-7.

7. Jeong K, Kang E, Kim K, Oh Y, Oh M, Lee Y, et al. Analysis of the survey of living conditions and welfare needs of older Koreans 2017. Korea Institute for Health and Social Affairs; 2017 Nov. Report No.: 11-1352000-000672-12.

8. Ministry of the Interior and Safety. Report from Ministry of the
Interior and Safety in 2017 [Internet]. Sejong: Ministry of the Interior and Safety [cited 2018 Sep 21]. Available from: https://www. mois.go.kr/frt/bbs/type001/commonSelectBoardArticle.do?bbsId= BBSMSTR_000000000245\&nttId=57300.

9. Statistics Korea. E-national index services [Internet]. Statistics Korea: Daejeon: Statistics Korea [cited 2018 Sep 21]. Available from: www.index.go.kr/.

10. Health Insurance Review \& Assessment Service. Annual Health Insurance Statistics for 2016 [Internet]. Wonju: Health Insurance Review \& Assessment Service; 2017 [cited 2018 Sep 21]. Available from: https://www.hira.or.kr/bbsDummy.do?pgmid=HIRAA0 20045020000\&brdScnBltNo=4\&brdBltNo=2309\&pageIndex=1.

11. Korea Centers for Disease Control \& Prevention. Korea health statistics 2016: Korea national health and nutrition examination survey [Internet]. Sejong: Ministry of Health \& Welfare; 2017 [cited 2018 Aug 1]. Available from: https://www.cdc.go.kr/CDC/ contents/CdcKrContentView.jsp?cid=60949\&menulds=HOME001MNU1130-MNU1639-MNU1749-MNU1761.

12. OECD. Health at a glance 2011: OECD indicators. Paris: OECD Publishing; 2016.

13. Bierman AS. Functional status: the six vital sign. J Gen Intern Med 2001;16:785-6.

14. Lim S, Kim JH, Yoon JW, Kang SM, Choi SH, Park YJ, et al. Sarcopenic obesity: prevalence and association with metabolic syndrome in the Korean Longitudinal Study on Health and Aging (KLoSHA). Diabetes Care 2010;33:1652-4.

15. Kim KM, Lim S, Choi KM, Kim JH, Yu SH, Kim TN, et al. Sarcopenia in Korea: prevalence and clinical aspects. J Korean Geriatr Soc 2015;19:1-8.

16. Jang IY, Jung HW, Lee CK, Yu SS, Lee YS, Lee E. Comparisons of predictive values of sarcopenia with different muscle mass indices in Korean rural older adults: a longitudinal analysis of the aging study of PyeongChang rural area. Clin Interv Aging 2018;13:91-9.

17. Kim S, Kim M, Won CW. Validation of the Korean version of the SARC-F questionnaire to assess sarcopenia: Korean frailty and aging cohort study. J Am Med Dir Assoc 2018;19:40-5.e1.

18. Park MH, Ha JC, Shin IH, Kim HG, Lee SY, Jo JH, et al. Korean geriatric survey report 2008. Sejong: Ministry of Health \& Welfare; 2009 Feb. Report No.: 11-1351000-000316-12.

19. Jung HW, Kim SW, Ahn S, Lim JY, Han JW, Kim TH, et al. Prevalence and outcomes of frailty in Korean elderly population: comparisons of a multidimensional frailty index with two phenotype models. PLoS One 2014;9:e87958.

20. Kim KJ, Shin J, Choi J, Won CW. Discrepancies in the prevalence of known frailty scales: Korean frailty and aging cohort study. Ann Geriatr Med Res 2018;22:137-44. 